\title{
RAIL PASSENGER EQUIPMENT CRASHWORTHINESS TESTING REQUIREMENTS AND IMPLEMENTATION
}

\author{
David Tyrell \\ Kristine Severson \\ Volpe National Transportation Systems Center \\ US Department of Transportation \\ Cambridge, MA 02142 USA
}

\section{A. Benjamin Perlman \\ Tufts University \\ Medford, MA 02155}

\author{
Barrie Brickle \\ Transportation Technology Center, Inc. \\ Association of American Railroads \\ Pueblo, CO 81001 USA
}

\author{
Caroline VanIngen-Dunn \\ Simula Technologies, Inc. \\ Phoenix, AZ
}

\begin{abstract}
This paper describes the requirements and the implementation of a series of impact tests of rail passenger equipment. The test requirements - the desired measurements - are dictated by the characteristics of the vehicle, as well as uncertainties in the analysis techniques used to evaluate the collision behavior of the equipment. The required measurements are implemented with available measurement transducers, including accelerometers, strain gages, and string potentiometers. The measurement data are gathered using an on-board data acquisition system.
\end{abstract}

\section{INTRODUCTION}

The approach taken by the Federal Railroad Administration's (FRA) Office of Research and Development in conducting research into rail equipment crashworthiness has been to review relevant accidents and identify options for design modifications. Analytic tools and testing techniques are used to evaluate the effectiveness of these options.

As part of this research, computer models have been developed and applied to determine the response of rail equipment in a range of collision scenarios $[1,2,3,4,5,6]$. In-line and oblique train-to-train collisions, as well as grade crossing collisions and rollover events subsequent to derailment have been modeled. The responses of locomotives, cab cars, and coach cars in a range of collision scenarios have been simulated.

To assess the validity of the models, results of these analyses have been compared with accident data, and component test results [7]. While providing useful information and some assurance of the validity of the models, accident data and component and subscale testing all have limitations. There is uncertainty about the initial conditions of any accident - the precise speeds and locations of the two colliding objects are never precisely known. In addition, there is no information on the trajectories of the objects involved in the collision which lead to their resting places; this information must be inferred from the results of the accidents. The support and loading conditions in component tests can only approximate the actual conditions these components experience during a collision.
Competing modes of crush (e.g., bending, bulk crushing, and material failure) cannot be consistently scaled for subscale testing [8]. Either one mode of crush must be chosen as the dominant mode and the other modes ignored, or it must be assumed that the simulation accurately scales the competing modes. Full-scale impact tests are necessary in order to know precisely the initial conditions, to measure the trajectories of the equipment during the impact, and to provide the appropriate support conditions for the structure that crushes during the impact, as well as to allow the competing modes of crush to appropriately contribute to the overall crush of the structure.

A series of tests have been planned to measure the crashworthiness performance of existing design equipment and to measure the performance of equipment incorporating crushable end structures. The collision scenario addressed by these tests is a locomotive-led passenger train colliding with a cab car led passenger train on tangent track. The tests planned for each equipment type are:

1. Single-car impact into a fixed barrier

2. Two coupled car impact into a fixed barrier

3. Cab car-led train collision with standing locomotive-led train

The overall objectives of these tests are to demonstrate the effectiveness of:

- improved-crashworthiness cab car structural designs

- improved-crashworthiness coach car structural designs

- a variety of occupant protection strategies.

To date, the first two tests for existing-design equipment have been conducted. The third test, to complete the characterization of the performance of existing design equipment in an in-line collision, is planned for November 2000. Testing of improved crashworthiness design equipment, incorporating crushable end structures, is planned to start in the spring of 2001.

\section{PLANNED TESTS}

The planned tests are based on a head on-collision scenario, in which a cab car-led train collides with a locomotive led train. Figure 1 shows a schematic representation of such a collision. Examples of such 
collisions include the Prides Crossing, Massachusetts collision between a commuter train and a freight train [9] and the Silver Spring, Maryland collision between a commuter train and an intercity passenger train [10].

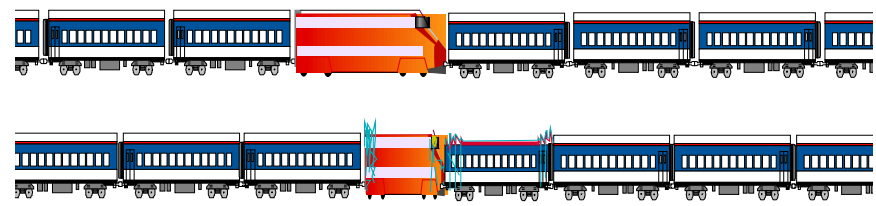

Figure 1. Schematic of In-Line Collision Scenario

The conditions for these tests and the sequences of the tests are listed in Table 1. The overall objective of these tests is to demonstrate the effectiveness of improved-crashworthiness equipment. The first three tests define the crashworthiness of conventional equipment. The performance of improved-crashworthiness equipment is to be measured in the second three tests. This arrangement of the tests allows comparison of the conventional equipment performance with the performance of improved-crashworthiness equipment. These tests are intended to measure the crashworthiness of a single car, then the interactions of two such cars when coupled, and finally the behavior of complete trains, including the interactions of the colliding cars.

Table 1. Planned Sequence of Full-scale Passenger Equipment Impact Tests

\begin{tabular}{|l|c|c|}
\hline Test Conditions & $\begin{array}{c}\text { Conventional } \\
\text { design equipment }\end{array}$ & $\begin{array}{c}\text { Crash-energy } \\
\text { management design } \\
\text { equipment }\end{array}$ \\
\hline $\begin{array}{l}\text { Single-car impact } \\
\text { with fixed barrier }\end{array}$ & $1^{\text {st }}$ Test & $4^{\text {th }}$ Test \\
\hline $\begin{array}{l}\text { Two coupled car } \\
\text { impact with fixed } \\
\text { barrier }\end{array}$ & $2^{\text {nd }}$ Test & $5^{\text {th }}$ Test \\
\hline $\begin{array}{l}\text { Cab car led train } \\
\text { impact with } \\
\text { locomotive led train }\end{array}$ & $3^{\text {rd }}$ Test & $6^{\text {th }}$ Test \\
\hline
\end{tabular}

Additional tests are currently under discussion by the industry and the Federal Government. Oblique impacts, in which the corner structure of a cab car is impacted, and impacts with heavy highway equipment are currently being considered. The potential bases for such tests include the oblique collision that occurred in Secaucus, NJ in February 1996 [11] when a cab car led train collided with a locomotive led train at a switch, and the grade crossing collision that occurred in Portage, IN, in July 1998, when a cab car collided with a tractor trailer carrying steel coils [12].

\section{Summary Description of Tests}

Figure 2 shows a schematic of the November 16, 1999 single-car test of a conventional design car, which was traveling at $35.1 \mathrm{mph}$ when it impacted the wall $[13,14]$. The objectives of this test were to observe the failure modes of the major structural components, to measure the gross motions of the car, to measure the force/crush characteristic, and to evaluate selected occupant protection strategies.

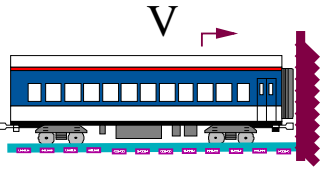

Figure 2. Schematic of Single-Car Test
Figure 3 shows a schematic of the April 4, 2000 two-car test of conventional design cars, which were traveling at $26.25 \mathrm{mph}$ when they impacted the wall $[15,16]$. This test had the same objectives as the single-car test conducted on November 16, 1999 with the addition of measuring the interactions between the coupled cars.

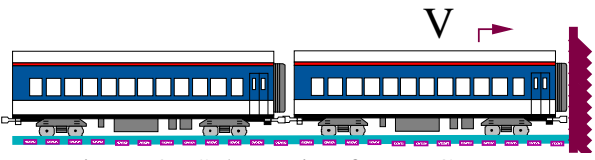

Figure 3. Schematic of Two-Car Test

Figure 4 shows a schematic of the train test. In this test, a cab car led train impacts a standing locomotive-led train. The locomotive is backed up by ballasted freight cars. This test has the same objectives as the two-car test, with the addition of measuring the interactions between the colliding locomotive and cab car. Conduct of this test is planned for November 2000. Simulations of the test are ongoing and the impact speed has not yet been chosen.

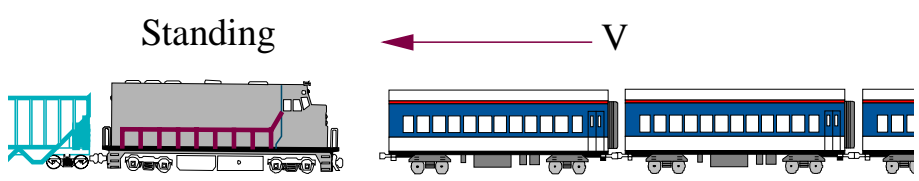

Figure 4. Schematic of Train Test

Figure 5 shows schematic illustrations of the passenger protection strategies tested in the single-car and two-car tests. All three strategies were tested in the single-car test and in the leading car in the two-car test. The trailing car in the two-car test also tested the forward facing unrestrained occupant protection strategy. It is currently planned that all three passenger protection strategies will be tested in the train-totrain test. However, the locations in the cab car led train have not yet been finalized. The principal objective of these tests is to measure the responses of test dummies in several interior configurations.

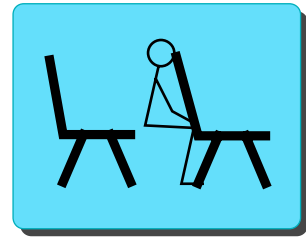

Forward Facing Occupant

(1)

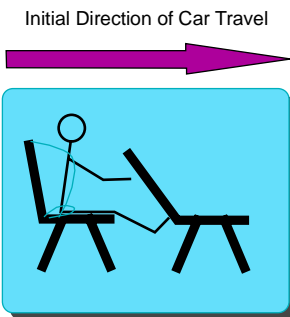
and Shoulder Harness

(2)
Occupant with Lap Belt

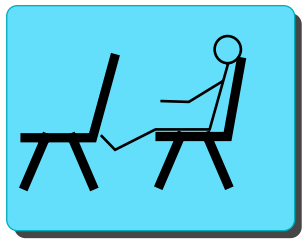

Rear Facing Occupant

(3)
Figure 5. Schematics of Passenger Protection Strategies

Figure 6 shows a schematic illustration of the locomotive operator's interior environment to be tested during the train to train test. The objective of this test is principally to observe the kinematics of the test dummy, as well as to measure the test dummy response.

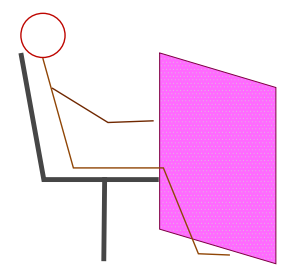

Figure 6. Schematic of Locomotive Operator Interior Test 
Table 2 summarizes the critical measurements for each of the three tests. While the overall objective of these tests is to demonstrate the effectiveness of improved-crashworthiness equipment, the test data are also being used for comparison with analyses and modeling results. The measurements will be used to refine these analyses approaches and models, and to assure that the factors influencing the response of the equipment and test dummies are taken into account. The table lists the measurements that are critical to assuring the appropriate modeling and analysis of the equipment and test dummies.

Table 2. Test Descriptions and Critical Measurements

\begin{tabular}{|l|ll|}
\hline $\begin{array}{l}\text { Test } \\
\text { Description }\end{array}$ & Critical Measurement \\
\hline $\begin{array}{l}\text { Single-Car } \\
\text { Dynamic } \\
\text { Crush Test }\end{array}$ & - & $\begin{array}{l}\text { Dynamic crush force } \\
\text { Loss of occupant volume } \\
\text { Occupant volume deceleration, }\end{array}$ \\
& - & $\begin{array}{l}\text { Effectiveness of compartmentalization, rear- } \\
\text { facing seats, and seats with lap and shoulder } \\
\text { belts }\end{array}$ \\
\hline $\begin{array}{l}\text { Test of } \\
\text { Two } \\
\text { Caupled }\end{array}$ & - & $\begin{array}{l}\text { Influence of trailing car on maximum } \\
\text { Occupant volume deceleration, }\end{array}$ \\
& - & $\begin{array}{l}\text { Effectiveness of compartmentalization, rear- } \\
\text { facing seats, and seats with lap and shoulder } \\
\text { belts }\end{array}$ \\
\hline Train Test & - & $\begin{array}{l}\text { Lateral buckling of coupled cars, } \\
\text { Override of colliding cars } \\
\text { Effectiveness of compartmentalization, rear- } \\
\text { facing seats, and seats with lap and shoulder } \\
\text { belts } \\
\text { Measurement of operator secondary collision } \\
\text { environment }\end{array}$ \\
\hline
\end{tabular}

\section{TEST REQUIREMENTS}

Requirements for testing include the specification of the equipment to be tested, the conditions for the test, and the information to be gathered during the test. For the single-car test, requirements were developed from the results of car crush, train dynamics, and occupant response simulations. For the occupant protection experiments, the requirements for previous sled testing were also considered [17]. The two-car test requirements were developed from simulations, as well as the experience gained in performing the single-car test. Similarly, the requirements for the train test are being developed from simulations of that test, as well as from the experience gained in the single-car and two-car tests.

\section{Pre-Test Modeling and Simulation}

The simulations have been used to bound the range of potential responses of the equipment and the dummies inside the cars. The results have been used for determining critical measurements, the sizing and the placement of instruments, and the location of dummies for the occupant protection tests. A three-step approach is used to simulate the tests:

Step 1: Car Crush Behavior. Detailed dynamic, non-linear, large displacement finite-element models of the structures are developed. The principal purpose of these models is to calculate the force/crush behavior for use in the crush elements of the collision dynamics models.

Step 2: Train Collision Dynamics. Plane and Threedimensional lumped-mass collision dynamics models are developed and applied to determine the trajectories of the equipment. Impact elements are used in these collision dynamics models, with the parameters for these elements taken from the results of the finiteelement analyses of car crush behavior.

Step 3: Occupant Response. The occupant volume reduction and decelerations developed from the collision dynamics models are used to determine the response of the occupants during a train collision, and the loads imparted to the seats and other interior fixtures.

\section{Single-Car Test}

The equipment tested during the single-car test was a cab car of conventional design built to North American standards. Figure 7. shows a schematic illustration of the major structural elements of a conventional single-level passenger car. In a typical arrangement, the operator stands on a plate over one of the step wells in order to operate the train.

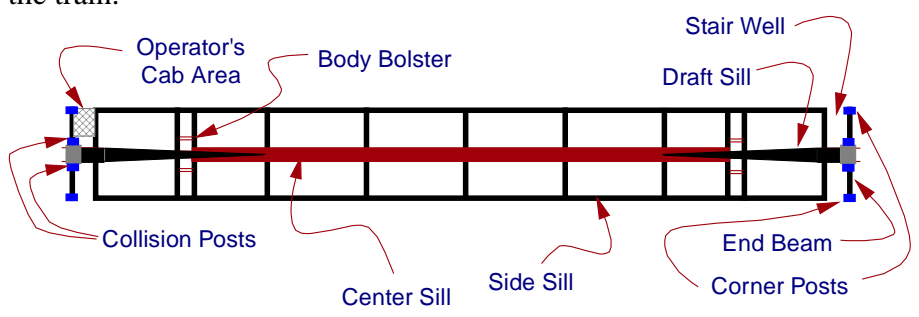

Figure 7. Schematic of Typical Cab Car Structural Members, Top View

The North American standard that most influences the collapse pf the car structure is the requirement for 800 kips buff strength. This standard requires that the complete car be able to support an $800 \mathrm{kip}$ squeeze load applied to the buff stops, which are located on the draft sill approximately 4 feet in from the end of the car, without permanent deformation. This requirement has been in effect since 1939 [18] and continues to be in effect $[19,20]$. Most of the recent changes to North American practice for passenger equipment used at speeds less than $125 \mathrm{mph}$ have been to the end structure of the car, i.e., the collision post and corner post requirements. These elements do not influence the longitudinal strength of the car. The buff strength requirement does influence the longitudinal strength of the car.

The test conditions are intended to produce substantial damage to the car structure. At least three feet of crush was desired in order to measure the data necessary to evaluate the effectiveness of models in predicting large amounts of structural damage. The simulation results indicated an impact speed of $35 \mathrm{mph}$ with a fixed barrier was necessary in order to produce three to five feet of crush (reduction in length) of the carbody.

Required Information. For the single-car test the information desired on structural crashworthiness included: - the force imparted to the wall during the test,

- $\quad$ the relative loadings carried by the longitudinal structural members,

- $\quad$ the mode of crush of the carbody (i.e., the series of geometric changes the car structure undergoes as it crushes,)

- the elastic vibratory motions of the carbody,

- the gross motions of the car, including the longitudinal, vertical and lateral accelerations and displacements,

- $\quad$ the gross motions of the trucks, including the longitudinal, vertical and lateral accelerations and displacements, and

- $\quad$ the displacements across the suspension elements. 
The force/crush characteristic (i.e., the load that the car structure develops as it collapses) is a key characteristic of the crashworthiness of a car. Analytically, this information is often calculated with detailed finite element models that incorporate the geometry of the structure and the properties of the material. This information is then used in models of the entire train to determine the distribution of crush among the cars of the train and the decelerations of each of the cars. If the force/crush characteristic is incorrect, then the results of the train model will also be incorrect. One purpose of the test is to make measurements for comparison with analytic predictions in order to assure that such predictions are accurate.

The mode of crush is particularly difficult to calculate for strengthdesign structures, such as conventional North American design rail passenger cars. The mode is sensitive to small imperfections in the structures [21]. Because of the sensitivity to small imperfections, precise agreement between the mode predicted by analysis and that observed during the test is not likely.

The vertical and lateral motions of the car are of particular interest in the test. Any vertical or lateral forces that develop as the car crushes can elicit a response from the suspension. Analysis results indicate that small lateral or vertical forces, relative to the longitudinal force, are required in order to cause significant vertical and lateral carbody motions. Such forces may come about because the structure effectively forms a ramp as it crushes. It is likely that the combination of the vertical forces and suspension response influence the potential for override.

The desired information on occupant protection for each of the interior configurations includes:

- the potential for occupant injury

- the kinematics of the occupants

- loads imparted to the seats

There are currently criteria for head, neck, chest, and femur injury used in the automotive industry [22]. These criteria relate acceleration and force measurements to the potential for human injury. It was desired to make the measurements required for comparison with the criteria for the three interior configurations. These measurements would also be useful for comparison with previous analyses predictions and sled test measurements.

It was particularly desired to gather information on the influence of the vertical and lateral motions of the car on the occupant kinematics. Previous analyses and sled testing have been one-dimensional, i.e, the vertical and lateral accelerations have been neglected. The information gathered during the test will be used to evaluate the assumption that the longitudinal deceleration dominates to such a degree that the lateral and vertical motion can be neglected in evaluating occupant protection strategies.

In order to be effective in providing compartmentalization for unrestrained occupants, the seats and interior fixtures must remain attached during a collision. It was desired to measure the loads imparted to the seats. Such information can be used for comparison with simulation analyses, as well as in development of future seat designs.

\section{Two-car Test}

Requirements for the equipment tested in the two-car test were the same as in the single-car test, i.e., equipment built to North American standards. The only difference being that two coupled cars impacted the fixed barrier in the two-car test.

Like the single-car test, it was desired that the test conditions produce substantial damage to the car structure, i.e., three to five feet of crush. The simulation results indicated an impact speed of $26 \mathrm{mph}$ with a fixed barrier was necessary in order to produce three to five feet of crush (reduction in length) of the leading carbody. The simulation results also indicated that essentially all of the crush would be focused at the leading end of the leading car with very little crush at the trailing end of the leading car or at the leading end of the trailing car.

Required Information. The required information for the two-car test was the same as for the single-car test, with the addition of information on the interactions of the coupled cars.

Simulations made prior to the test indicated that the coupled cars would sawtooth buckle, as illustrated in Figure 8. Schematic (a) shows the coupler in its nominal position, schematic (b) shows the coupler when it has buckled, and schematic (c) shows the cars when a sawtooth buckle has occurred. It was desired to gather information on the forces acting on the coupler and the timing of the buckle, i.e., when the buckle occurred in relation to the crush of the leading car. This information is required for comparison with simulation predictions to assure that the coupler and its behavior is being appropriately modeled.

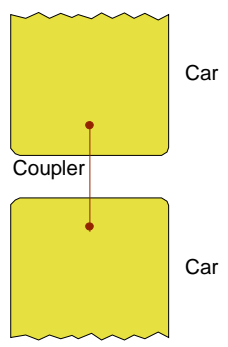

(a)

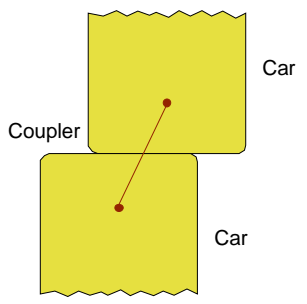

(b)

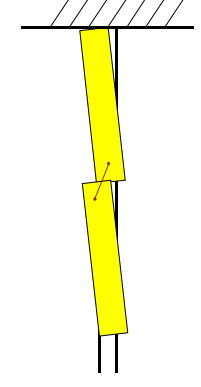

(c)
Figure 8. Schematics of Sawtooth Lateral Buckling (adapted from reference [4])

The desired information on the interactions of the coupled cars includes:

- $\quad$ longitudinal force acting on the couplers

- the longitudinal, lateral, and vertical displacements of the couplers relative to the respective carbodies

- the longitudinal, lateral, and vertical displacements of the cars relative to each other

\section{Train Test}

The equipment requirements for the train test are the same as for the single-car and two-car tests, i.e., equipment built to North American standards. In addition to cab and coach cars, this test also requires a locomotive. The requirement for the locomotive is that it comply with AAR standard S-580 [23]. Since there is a potential for either the locomotive overriding the cab car or vice versa, the cab car end 
structure (collision posts and corner posts) must also comply with current APTA standards [21] and FRA regulations [20].

The details of the test conditions for the train test are currently being finalized. It is desired to cause substantial damage to the leading cab car and to the coach immediately trailing behind it.

Required Information. In addition to the information gathered during the single-car and two-car tests, it is also desired to gather information on the interactions between the colliding vehicles. There is a potential for override to occur during the test. Override occurs owing to the combined effects of the initial geometry of the vehicles (e.g., sill heights,) crush of the vehicle structures, and the responses of the vehicles on their suspensions. Information on each of these factors is required to assure that each of these factors is appropriately taken into account in simulation models.

The desired information on the interactions of the colliding locomotive and cab car includes:

- longitudinal, vertical, and lateral forces at the colliding interface

- the longitudinal, lateral, and vertical displacements of the colliding locomotive and car car relative to each other

\section{TEST IMPLEMENTATION}

The test implementation consists of the equipment tested, the track and fixtures used in the test, the instrumentation, the data acquisition the test procedures. The tests are being conducted at the US Department of Transportation's Transportation Technology Center (TTC) in Pueblo, Colorado.

\section{Single-Car Test}

Equipment. A Budd Pioneer cars was used in the single-car test [24]. A photograph of the car is shown in Figure 9. These cars include a stainless-steel body shell with a high-strength low-alloy steel underframe. They were designed to the Association of American Railroads Passenger Equipment Standards and Recommended Practices [25], including the 800,000-pound buff-strength requirement. The underframe design of the car is similar to the underframe design of most single-level passenger coach and cab cars used in North America, including the Amtrak Amfleet cars.

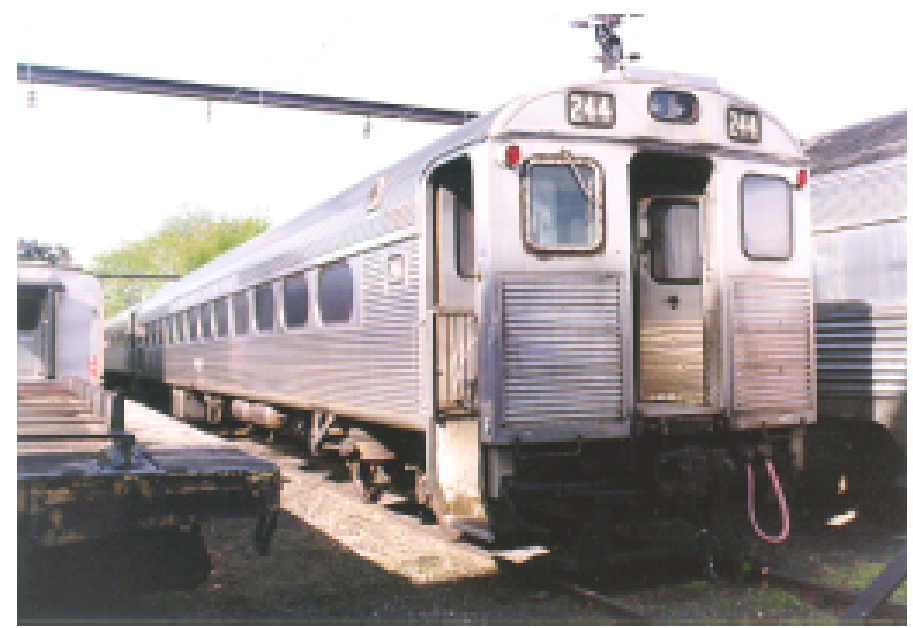

Figure 9. Budd Pioneer Car Used in Single-Car Test.

Three 3-place passenger, right-side (seat/wall attachment is on the right side of the seat), M-style seats from Coach and Car Equipment
Corporation (CCEC) were used in two of the three interior experiments: experiment 1 of two rows of forward facing seats and experiment 3 of one row of rear facing seats. This seat is shown in Figure 10, a photograph of experiment 1 . Two 2-place passenger, Amtrak inter-city seats were used in the third of the three interior experiments. One 2-place seat was modified with lap and shoulder belts. These seats are shown in Figure 11, a photograph of interior experiment 3 .

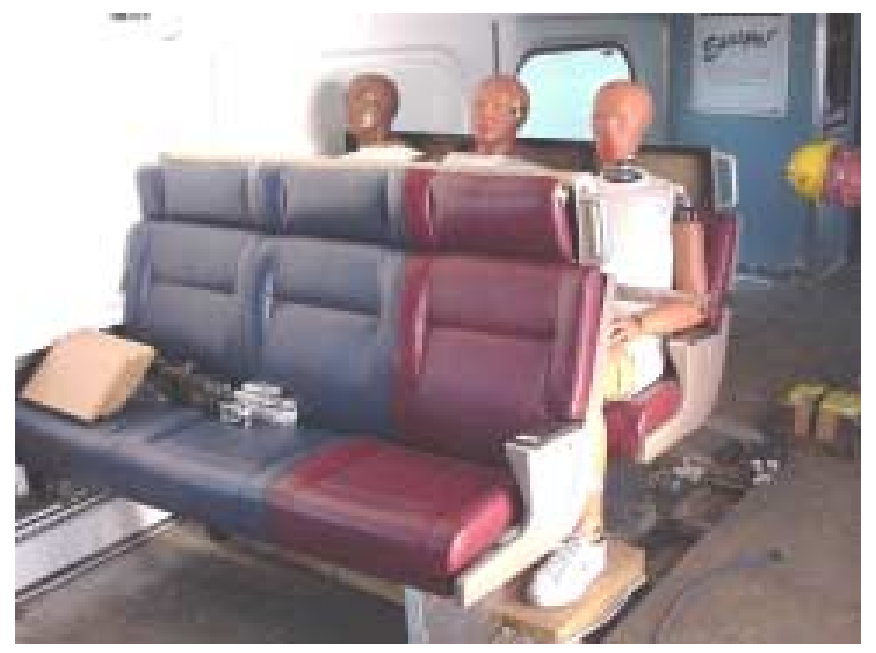

Figure 10. Coach and Car Equipment Corporation M-Style Commuter Passenger Seats

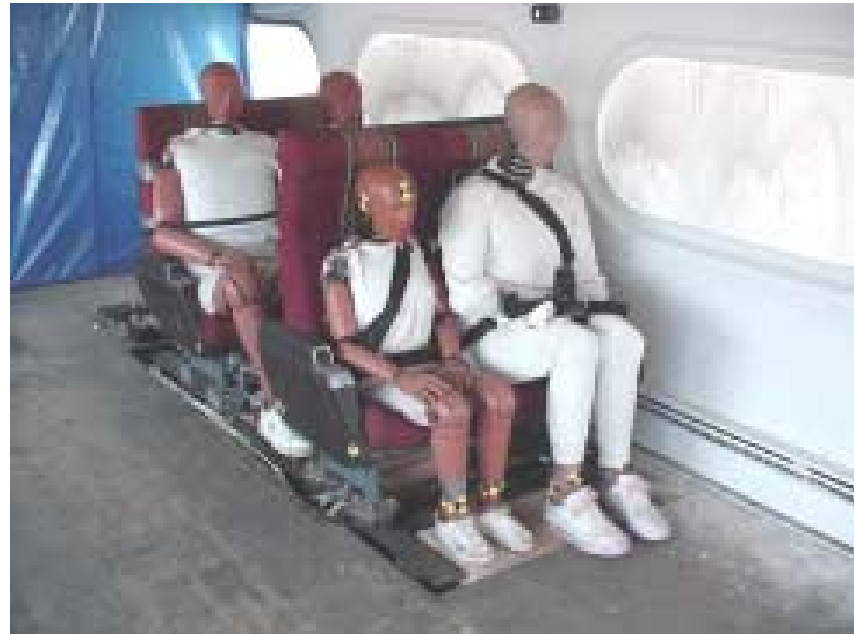

Figure 11. Amtrak Traditional Coach Seats, Leading Seat Modified with Lap and Shoulder Belts

Figure 12 shows the locations in the car of the interior test configurations. Configurations 1 and 3 were placed near the rear of the car because simulations indicated the potential for the front of the car to rise during the test, and the rear of the car to sink. With the car sinking and the dummies tending to remain at the same elevation, there is a greater potential for the test dummies to be catapulted over the seat ahead when the secondary impact occurs. 


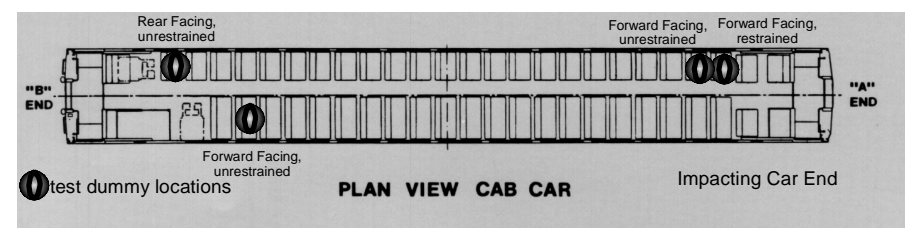

Figure 12. Location in the car of interior test configurations

Track and Fixtures. A photograph of the barrier used in the single-car test is shown in Figure 13. A detailed description of the crashworthiness test facilities at TTC is presented in reference [26]. The front wall of the barrier is 2 feet thick reinforced concrete, 25 feet wide by 18 feet high. This wall is supported by three vertical walls each 2 feet thick by 36 feet deep and 18 feet high. In between these three walls there are another two vertical support walls 18 inches thick by 20 feet deep and 8 feet high. Native soil has been compacted into the gaps between these walls and piled up against the two side walls and the rear. Over 1,000 tons of earth was used in the construction. The front of the barrier is faced with a 3 -inch steel plate. The railway track leading to the barrier is straight (tangent) with a gradient of 0.86 percent.

A concrete pad with the rails built-in has been constructed immediately in front of the wall. This concrete pad has a pit to allow a film camera and lights to be positioned looking up at the impact zone. Extra power outlets have been provided to either side of the wall and to the top of the wall, for film cameras and lights.

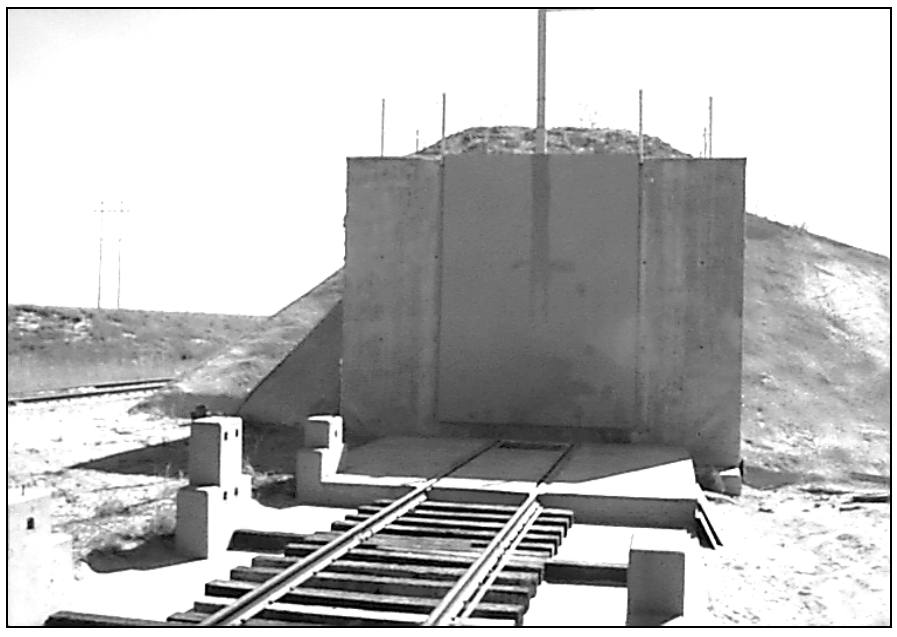

Figure13. Barrier Used in Single-Car Test

Instrumentation. Accelerometers, strain gages, displacement transducers, high-speed cameras, and instrumented dummies were used to gather data during the single-car test.

Accelerometers were used to make measurements in order to help determine:

the force imparted to the wall during the test,

- the elastic vibratory motions of the carbody,

- the gross motions of the car, including the longitudinal, vertical and lateral accelerations and displacements,

- $\quad$ the gross motions of the trucks, including the longitudinal, vertical and lateral accelerations and displacements.
The accelerations measured by the accelerometers include a contribution from the gross motion of the car, a contribution from the elastic vibrations of the car, and a contribution from the vibration of the accelerometer on its mounting. Because these three contributions cannot be completely separated, there is some uncertainty in the force calculated from the accelerations, as well as in the vibratory modes. High-speed cameras were used to record the collision, and the displacements of the car were determined by photometric analysis of the film. The displacements from the photometric analysis provide a cross-check for the displacements computed from the acceleration measurements.

Figure 14 shows the locations of the accelerometers for the single-car test. All the longitudinal accelerometers on the center and draft sills had a range of $400 \mathrm{~g}$ 's. Most of the lateral and vertical accelerometers on the carbody were either 100 or $200 \mathrm{~g}$ accelerometers, depending upon availability.

One dilemma was to choose accelerometers which would survive the environment yet be able to make measurements with adequate resolution. Increased accelerometer range decreases the accelerometer resolution, e.g., a $1000 \mathrm{~g}$ accelerometer may have a $10 \mathrm{~g} \mathrm{(1 \%} \mathrm{of} \mathrm{full}$ scale) steady state bias error while a $100 \mathrm{~g}$ accelerometer may have $1 \mathrm{~g}$ bias error. The underlying deceleration to be measured, the deceleration of the occupant volume, was expected to be approximately $16 \mathrm{~g}$ 's. Because of the elastic vibration of the carbody, the environment that the accelerometers would be subject to was expected to be significantly greater than $16 \mathrm{~g}$ 's, possibly much greater than $100 \mathrm{~g}$ 's. The dilemma was addressed by using a variety of accelerometers to measure longitudinal deceleration on the side sills. $1000 \mathrm{~g}$ accelerometers were used at locations R-1 and L-1. $400 \mathrm{~g}$ accelerometers were used at locations R-2, R-5, L-2, and L-5. $100 \mathrm{~g}$ accelerometers were used at locations R-4 and L-4. Tri-axial accelerometers, with a maximum range of $400 \mathrm{~g}$ 's in each direction, were placed on a side sill of each truck.

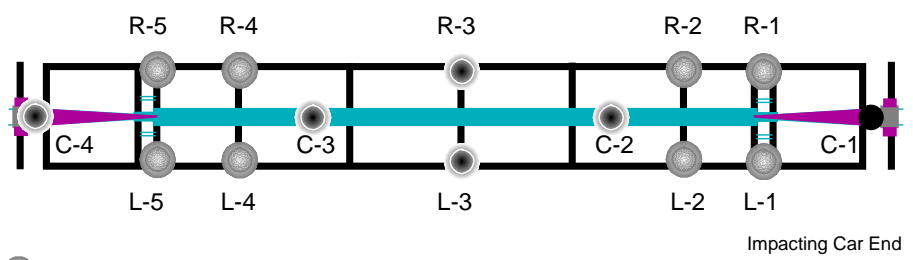

Three-axis Accelerometer Locations

Two-axis (vertical and lateral) Accelerometer Locations

Single-axis (longitudinal) Accelerometer Location

\section{Underframe Plan View}

Figure 14. Schematic Layout of Single-Car Test Accelerometer Locations

Strain gages were used to make measurements in order to help determine:

- $\quad$ the relative loadings carried by the longitudinal structural members

- $\quad$ the mode of crush of the carbody (i.e., the series of geometric changes the car structure undergoes as it crushes) 
Figure 15 shows the detailed arrangement of the high-elongation strain gages on the left side of the the cant rail, the draft and center sills, and the side sill. A total of forty-four high-elongation strain gages were used.

\begin{tabular}{|ccc}
\multicolumn{1}{c}{ CR-L-1-U } & CR-L-2-U & CR-L-3-U \\
\hline 品 & 品 & 品 \\
\hline CR-L-1-L & CR-L-2-L & CR-L-3-L \\
& & Cant Rail
\end{tabular}

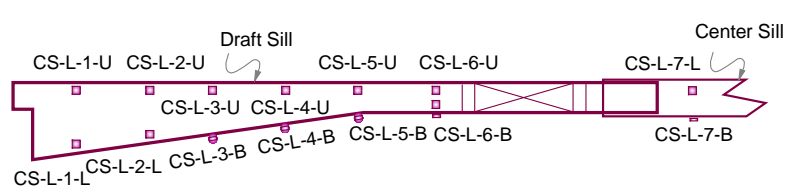

\section{Draft and Center Sills}

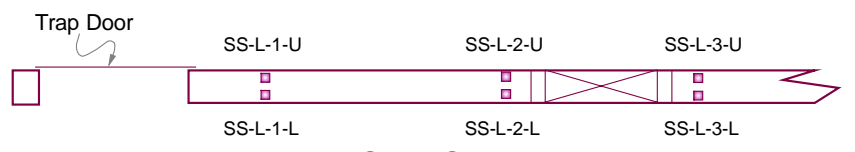

$\square$ High-Elongation Strain Gages Side Sill

Figure 15. Arrangement of high-elongation strain gages on the left cant rail, draft and center sills, and side sill

Displacement transducers were used to measure the the displacements across the suspension elements. Figure 16 illustrates the locations of the displacement transducers.

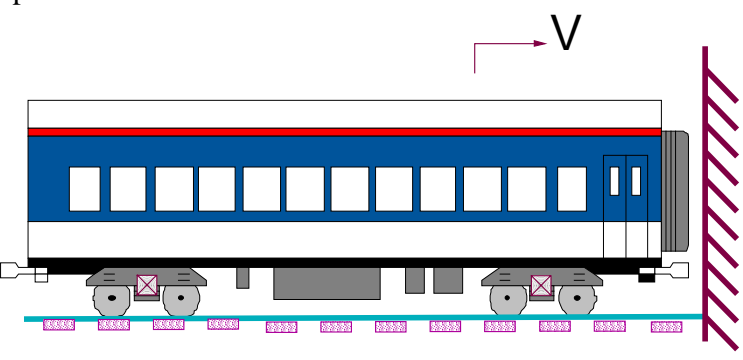

$\bigotimes$ Displacement Transducer Location

Figure 16. Schematic Layout of displacement transducers

For the structural portion of the test, high-speed cameras and real-time video cameras were used to record the impact and to gather information on:

- $\quad$ the mode of crush of the carbody (i.e., the series of geometric changes the car structure undergoes as it crushes,)

- the gross motions of the car, including the longitudinal, vertical and lateral displacements,

Figure 17 shows the locations of the cameras for the single-car test, and includes side view cameras, cameras looking down on the impact area, cameras looking up at the impact area from a recess between the rails, and an onboard camera looking at the crush zone. Supplemental lighting is required for the onboard camera to obtain good exposure; a trip wire attached to the test vehicle is set to trigger this camera and its lights at a pre-determined point. The side view cameras are located approximately 25 feet $(7.62 \mathrm{~m})$ away from the side of the car body and about 5 feet $(1.52 \mathrm{~m})$ in front of the barrier. The ground-based cameras are started simultaneously from a central relay box triggered manually.

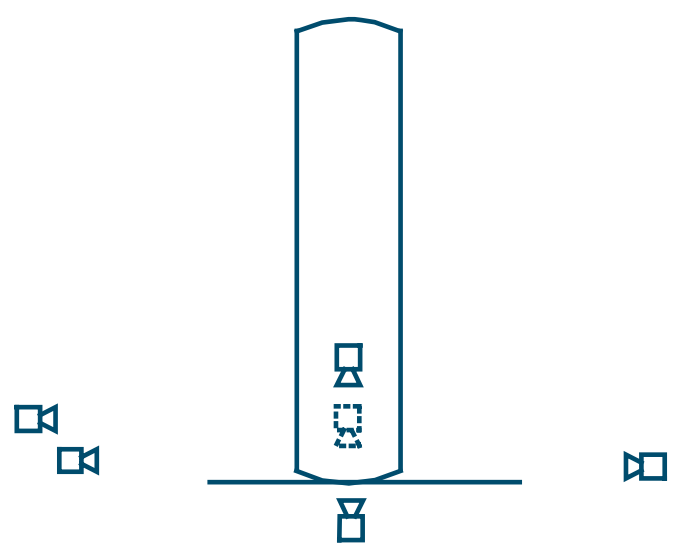

Figure 17. Schematic Layout of Structural High-Speed Camera Locations

The cameras used are usually set at $500 \mathrm{fps}$ or 1,000 fps. At 1,000 fps the cameras will run for about 4 seconds before 100 feet $(30.5 \mathrm{~m})$ of film is entirely exposed. A $100 \mathrm{~Hz}$ reference signal is placed on the film so that accurate frame speed can be determined from film analysis.

A number of 4-inch diameter targets are placed on the vehicle and the ground to facilitate post-test film analysis to determine speed and displacement of the vehicle structure during the impact. During film analysis, the longitudinal and vertical coordinates of the targets are determined from projections on a film analyzer on a frame-by-frame basis. The differences in locations between vehicle-mounted and ground-based targets quantify the motion of the vehicle during the test. By taking the position differences between vehicle-mounted and ground-based targets, the effects of film registration jitter in the highspeed cameras are minimized. Test vehicle position is determined directly as indicated above, and the vehicle speed is determined by dividing the displacement between adjacent frames by the time difference between the adjacent frames. If necessary, smoothing is applied to the displacement and speed data to compensate for digitization and other uncertainties.

Test dummies were used to:

- gather information on the kinematics of the occupants

- gather information on the potential for occupant injury

- $\quad$ impart loads to the seats

Information on the occupant kinematics was gathered using highspeed cameras. These cameras were similar to the cameras used to film the collapse of the car structure. A total of six cameras were used, providing two views for each interior configuration. Figure 18 shows a schematic layout of the high-speed cameras used to film the interior tests.

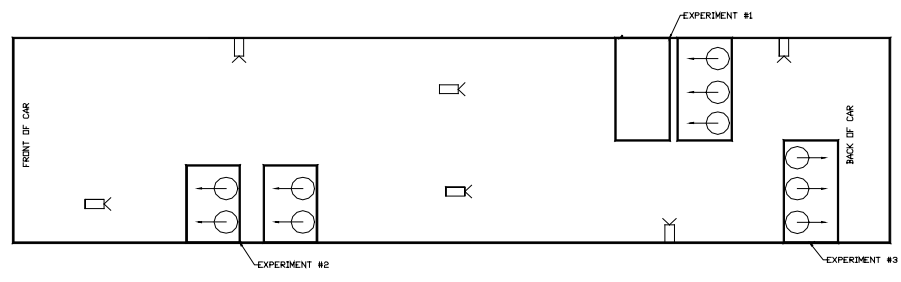

Figure 18. Schematic Layout of Occupant Protection High-Speed Camera Locations in Single-Car Test 
As shown in Figure 18, ten test dummies were used for the three occupant protection tests:

- $\quad$ Two Hybrid III $50^{\text {th }}$-percentile male

- $\quad$ Four Hybrid II $50^{\text {th }}$-percentile male

- $\quad$ Three $95^{\text {th }}$ percentile male

- $\quad$ One $5^{\text {th }}$ percentile female

The $50^{\text {th }}$ percentile male test dummies were used in interior configurations 1 and 3 . Two $95^{\text {th }}$ percentile males were used in the rear row of interior configuration 2 . One $95^{\text {th }}$ percentile male and the $5^{\text {th }}$ percentile female were used in the forward row of configuration 2. These two test dummies were restrained by lap and shoulder belts. Each test dummy was clothed in a form fitting, cotton stretch garment with short sleeves, and mid-thigh-length bottoms. The test dummies were also fitted with shoes that weigh approximately $2.5 \mathrm{lb}$.

Four of the test dummies were instrumented to measure the data required to evaluate occupant injury criteria. Figure 19 schematically illustrates the instrumentation on these four test dummies. One instrumented test dummy was used in interior configuration 1 , one in interior configuration 3 , and two in interior configuration $2-$ the restrained $5^{\text {th }}$ percentile female and the $95^{\text {th }}$ percentile male seated behind the $5^{\text {th }}$ percentile female.

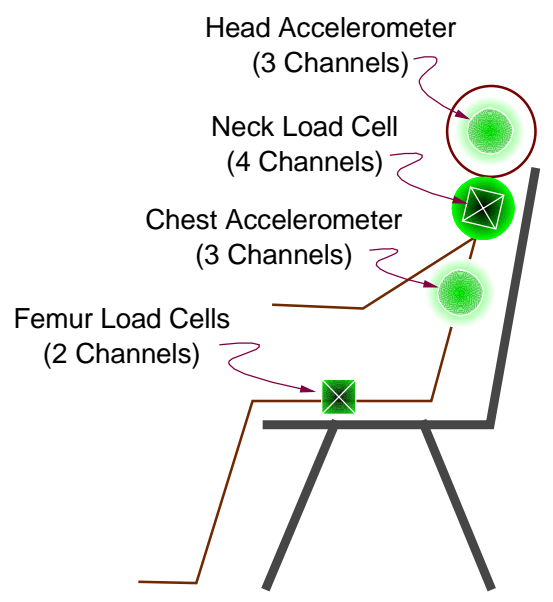

Figure 19. Schematic Illustration of Instrumented Test Dummies

Load cells were used to gather information on the loads imparted to the seats. The load cells were used to measure the force in the vertical, lateral, and longitudinal directions. Figure 20 shows the locations of the load cells for interior configuration 1 . The forward seat, the one initially without the test dummies, was instrumented with the load cells as that seat must sustain the impact load associated with the unrestrained test dummies. Interior configuration $3 \mathrm{had}$ a similar arrangement of load cells; in that configuration there is only one seat, the rear facing seat with the dummies. There was no impact load expected per se, but a high inertial load on that seat was expected due principally to the inertia of the test dummies.

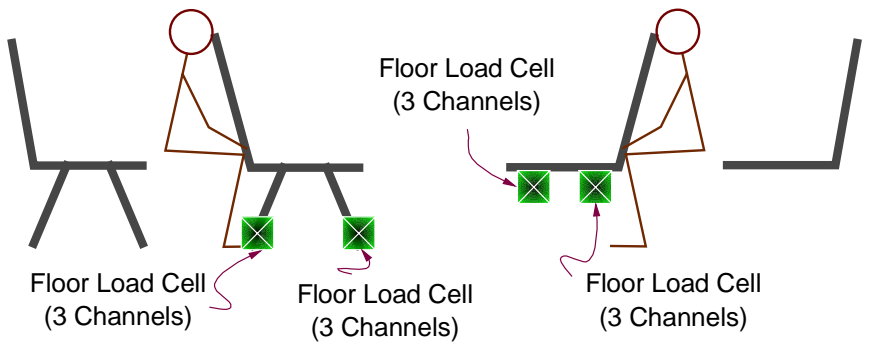

\section{Aisle Side Wall Side}

Figure 20. Schematic Illustration of Load Cell Locations in Interior Configuration 1

Figure 21 shows a schematic layout of the load cells used in interior configuration 2. Four load cells were used between the seat and the floor. Load cells were also used to measure the tension in the shoulder belt. This load is critical in such a seat, as it must be reacted through the seat itself. (In typical automotive applications, this load is directly supported by the vehicle structure.)

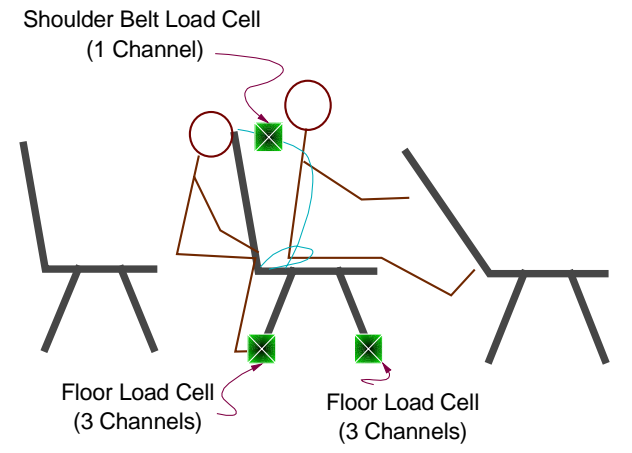

Figure 21. Schematic Illustration of Load Cell Locations in Interior Configuration 2

Data acquisition. An on-board data acquisition system was used to record the measurements from the accelerometers, strain gages and displacement transducers. Battery powered Data Bricks were used to provide 8-channels of data acquisition, excitation to the strain gages and accelerometers, analog anti-aliasing filtering of the signals, analog to digital conversion and recording. Data from each channel is recorded at a sample rate of $12,800 \mathrm{~Hz}$. All the instrumentation used complies with SAE J211/1, Instrumentation for Impact Tests (revised March 1995). Although this standard was developed for automotive impact testing there is nothing equivalent, as yet, for railway vehicle impact testing and so this standard was used.

All the recorded data is synchronized with a time reference applied to all systems simultaneously at the time of impact. This time reference comes from the closure of a tape switch on the front of the test vehicle in the leading contact position. Closure of these switches at impact will indicate contact between the test vehicle and the barrier. The switch closures will trigger each Data Brick and 0.1 second of pretrigger data is recorded in the Data Brick. The total amount of data recorded is 1.5 seconds.

Test procedures. Speed calibration tests were carried out on the track parallel to the barrier track. The test vehicle is released at a particular point and the speed of the car measured as it passes the 
barrier. Once several tests have been carried out at various release points, the release point for a particular speed can be calculated.

An onboard radar speed measurement device is used for the calibration tests and a laser speed trap, accurate to within 1 percent, is used to measure the speed of the vehicle just before impact with the wall.

The factors affecting the release distance are the rolling resistance of the vehicle on the track, the bearing resistance, the aerodynamic drag of the vehicle, and the gradient of the track. All these factors can be accounted for in the speed calibration tests and it has been shown possible to obtain impact speeds within 1 percent of the desired speed by careful speed calibration.

Knowing the release distance for a $35 \mathrm{mph}$ impact, the car was then allowed to run down the track into the barrier. In this way the desired speed of the vehicle at impact was accurately achieved. (The actual impact speed measured during the test was $35.1 \mathrm{mph}$.)

\section{Test 2: Two-car Test}

Implementation of the two-car test was similar to the single-car test. The number and types of accelerometers used were reduced based on the experience of the single-car test. Strain gages were used at the impact and trailing end of the leading car and the leading end of the trailing car, but there number was greatly reduced from the number shown in Figure 15.

The coupler on the trailing end of the leading car was instrumented with strain gages in order to measure:

- longitudinal force acting on the couplers

Both couplers were instrumented with three displacement transducers in order to measure:

- the longitudinal, lateral, and vertical displacements of the couplers relative to the respective carbodies

The arrangement for the coupler on the trailing car is shown in Figure 22 .

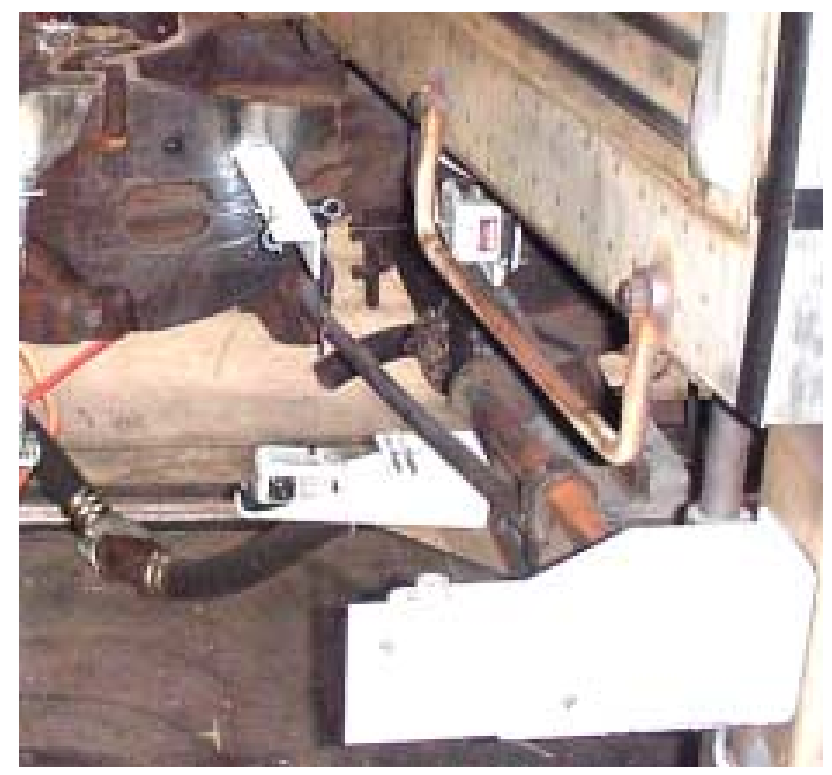

Figure 22. Photograph of Displacement Transducers on Coupler of Trailing Car
Interior configurations 1,2 , and 3 were tested in the leading car and interior configuration 1 was tested in the trailing car. Instrumentation for these interior configurations was nearly identical to the single-car. The placement of the high-speed cameras was changed somewhat from the first test in order to provide clearer views of the ATD kinematics.

\section{Test 3: Train Test}

Implementation of the train test is planned to be similar to the two-car test. In addition to the instrumentation on the couplers between cars, instrumentation is being developed in order to measure the interactions of the colliding locomotive and cab car, including:

- $\quad$ the longitudinal, vertical, and lateral forces at the colliding interface

- the longitudinal, lateral, and. vertical displacements of the colliding locomotive and cab car relative to each other

The three interior configurations will be tested in selected passenger cars. It is currently planned that an instrumented test dummy will be used in the operator's seat, and the operator's seat will be instrumented with one or more load cells.

\section{FUTURE PLANS}

Preliminary analyses of the single-car test and two-car test structural and occupant protection measurements have been completed $[14,15$, $16,17]$. The structural test measurements are currently being used to refine car the crush model, and to extend this model to simultaneously evaluate car crush and gross motions. The occupant protection measurements are currently being used to evaluate the influence of the vertical and lateral accelerations on occupant response, by comparison with previous sled test measurements. Efforts are ongoing to finalize the requirements and implementation of the train test.

Efforts are also underway to prepare for testing crash energy management design equipment. Significant improvements in crashworthiness performance are expected. For example, for the twocar test of crash energy management equipment it is expected that the car crush will be distributed among the leading and trailing ends of the leading car and the leading end of the trailing car. As a result of this distribution, there will be no intrusion into the occupant volume. In the two-car test of the conventional equipment, all the crush was focused on the leading end of the leading car, resulting in loss of occupant volume for the first row of passenger seats [16].

\section{ACKNOWLEDGEMENTS}

This work was performed as part of the Equipment Safety Research Program sponsored by the Office of Research and Development of the Federal Railroad Administration. The authors would like to thank Dr. Tom Tsai, Program Manager, and Claire Orth, Division Chief, Equipment and Operating Practices Research Division, Office of Research and Development, Federal Railroad Administration, for their support. The authors would also like to thank Gunars Spons, Federal Railroad Administration Resident Engineer at the Transportation Technology Center, for managing the full-scale test effort.

\section{REFERENCES}

[1] Mayville, R.A.,Stringfellow, R.G., Rancatore, R.J., Hosmer, T.P., 1995, "Locomotive Crashworthiness Research, Volumes 1 through 5" DOT/FRA/ORD-95/8.1-8.5.

[2] Tyrell, D.C., K.J. Severson, R.A. Mayville, R.G. Stringfellow, S. Berry, and A.B. Perlman, "Evaluation of Cab Car Crashworthiness 
Design Modifications," Proceedings of the 1997 IEEE/ASME Joint Railroad Conference, IEEE Catalog Number 97CH36047, 1997.

[3] Tyrell, D.C., K.J. Severson, and B.P. Marquis, Crashworthiness of Passenger Trains, U.S. Department of Transportation, DOT/FRA/ORD-97/10, 1998.

[4] Mayville, R.A., Rancatore, R.J., Tegler, L. 1999, "Investigation and Simulation of Lateral Buckling in Trains," Proceedings of the 1999 IEEE/ASME Joint Railroad Conference, April 13-15, 1999, IEEE Catalog Number 99CH36340, ASME RTD Volume 16.

[5] Tyrell, D., K. Severson, B. Marquis, E. Martinez, R. Mayville, Rancatore, R., Stringfellow, R., Hammand, and A.B. Perlman, "Locomotive Crashworthiness Design Modifications Study," Proceedings of the 1999 IEEE/ASME Joint Railroad Conference, April 13-15, 1999, IEEE Catalog Number 99CH36340, ASME RTD Volume 16, 1999.

[6] Stringfellow, R.G., Mayville, R.A., Rancatore, 1999, "A Numerical Evaluation of Protection Strategies for Railroad Cab Car Crashworthiness," Proceedings of the 8th ASME Symposium on Crashworthiness, Occupant Protection and Biomechanics in Transportation November 14-19, 1999; Nashville, Tennessee.

[7]Mayville, R.A., Hammond, R.P., Johnson, K.N., 1999, "Static and Dynamic Crush Testing and Analysis of a Rail Vehicle Corner Structural Element," Proceedings of the 8th ASME Symposium on Crashworthiness, Occupant Protection and Biomechanics in Transportation November 14-19, 1999; Nashville, Tennessee.

[8] Holmes, B.S. and J.D. Colton, "Application of Scale Modeling Techniques to Crashworthiness Research," Kenneth J. Saczalski, et al. Editors, Aircraft Crashworthiness, Charlottesville, VA: University Press of Virginia, 1975.

[9] National Transportation Safety Board, "Railroad Accident Report: Head-On Collision of Boston and Maine Corporation Extra 1731 East and Massachusetts Bay Transportation Authority Train No. 570 on Former Boston and Maine Corporation Tracks, Beverly, Massachusetts, August 11, 1981,” PB82-916301, NTSB-RAR-82-1, 1982.

[10] National Transportation Safety Board , "Collision and Derailment of Maryland Rail Commuter MARC Train 286 and National Railroad Passenger Corporation, AMTRAK Train 29 Near Silver Spring, MD on February 16, 1996"' RAR-97-02, PB97-916302 , 1997.

[11] National Transportation Safety Board, "Railroad Accident Report: Near Head-On Collision and Derailment of Two New Jersey Transit Commuter Trains Near Secaucus, New Jersey, February 9, 1996,” PB97-916301, NTSB-RAR-97/01, 1987.

[12] National Transportation Safety Board, "Railroad Accident Report - Collision between Northern Indiana Commuter Transportation District Eastbound Train 7 and Westbound Train 12 Near Gary, Indiana on January 18, 1993." Washington, D.C. 20594.

[13] Tyrell, D., Severson, K., Perlman, A.B., March, 2000, “Single Passenger Rail Car Impact Test Volume I: Overview and Selected Results," US Department of Transportation, DOT/FRA/ORD-00/02.1.

[14] VanIngen-Dunn, C., "Single Passenger Rail Car Impact Test Volume II: Summary of Occupant Protection Program," U.S. Department of Transportation, DOT/FRA/ORD-00/02.2, March 2000.
[15] Severson, K., Tyrell, D., Perlman, A.B., "Rail Passenger Collision Tests: Analysis of Structural Measurements," to be presented at the 2000 ASME Winter Annual Meeting

[16] Tyrell, D., Zolock, J., VanIngen Dunn, C., "Rail Passenger Collision Tests: Analysis of Occupant Protection Measurements," to be presented at the 2000 ASME Winter Annual Meeting

[17] Tyrell, D., and K.J. Severson, "Crashworthiness Testing of Amtrak's Traditional Coach Seat," DOT/FRA/ORD-96/08, October 1996.

[18] Woodbury, C.A., $3^{\text {rd }}$, "North American Passenger Equipment Crashworthiness: Past, Present, and Future," in "Rail Vehicle Crashworthiness Symposium,” DOT/FRA/ORD-97/08, 1998.

[19] U.S. Department of Transportation, Federal Railroad Administration, "49 CFR Part 216 et al., Passenger Equipment Safety Standards; Final Rule,” Federal Register, May 12, 1999.

[20] American Public Transportation Association, "Manual of Standards and Recommended Practices for Rail Passenger Equipment," July 1, 1999.

[21] Hanefi, E.H., and T. Wierzbicki, "Calibration of Impact Rigs for Dynamic Crash Testing," Joint Research Center, European Commission Institute for Safety Technology, Report EUR 16347 EN, 1995.

[22] U.S. Department of Transportation, National Highway Transportation Administration, "49 CFR Part 552, 571, 585 and 595, RIN 2127-AG70 "Federal Motor Vehicle Safety Standards; Occupant Crash Protection,” May 2000.

[23] Association of American Railroads Technical Services Division, Mechanical Section - Manual of Standards and Recommended Practices, "Locomotive Crashworthiness Requirements, Standard S580," Adopted: 1989, Revised, 1994.

[24] White, J.H., Jr., "The American Railroad Passenger Car," The Johns Hopkins University Press, 1978.

[25] Association of American Railroads, "Manual of Standards and Recommended Practices, Section A, Part III: Passenger Car Requirements," Washington, D.C., 1980 (Revised 1983 and 1984).

[26] Brickle, B., "Crashworthiness Testing of Rail Passenger Cars" Proceedings of the 2000 IEEE/ASME Joint Railroad Conference, ASME RTD Volume 17, April 4-6, 2000. 